\title{
A Model of Cascading Change: Orchestrating Planned and Emergent Change to Ensure Employee Participation
}

\author{
Edwards, Kasper; Prætorius, Thim; Nielsen, Anders Paarup
}

Published in:

The Journal of Change Management

Link to article, DOI:

$10.1080 / 14697017.2020 .1755341$

Publication date:

2020

Document Version

Peer reviewed version

Link back to DTU Orbit

Citation (APA):

Edwards, K., Prætorius, T., \& Nielsen, A. P. (2020). A Model of Cascading Change: Orchestrating Planned and Emergent Change to Ensure Employee Participation. The Journal of Change Management, 20(4).

https://doi.org/10.1080/14697017.2020.1755341

\section{General rights}

Copyright and moral rights for the publications made accessible in the public portal are retained by the authors and/or other copyright owners and it is a condition of accessing publications that users recognise and abide by the legal requirements associated with these rights.

- Users may download and print one copy of any publication from the public portal for the purpose of private study or research.

- You may not further distribute the material or use it for any profit-making activity or commercial gain

- You may freely distribute the URL identifying the publication in the public portal

If you believe that this document breaches copyright please contact us providing details, and we will remove access to the work immediately and investigate your claim. 


\title{
A Model of Cascading Change:
}

\section{Orchestrating Planned and Emergent Change to Ensure Employee Participation}

\begin{abstract}
Understanding how and why organizational changes succeed is of paramount importance because many organizational changes do not deliver the expected results. This paper presents a case study of successful change at a world leading cardiology department and proposes a model of cascading change that requires change managers to go beyond the simplistic dichotomies of planned versus emergent change. Successful change requires the reconciliation and integration of top-down and bottom-up approaches. Top management must set the direction and should then step back and allow the diagnosis and solution-development processes to take place in a bottom-up manner. This allows employees to identify and solve the problems that matter to them and that reflect their organizational reality. The implementation of the changes toward the end of the change process should take place in a top-down manner. The cascading model of change is based on three key drivers: a cascading change process with formal handovers engaging more and more employees, Lewinian change processes of unfreeze, move, and refreeze, and, finally, orchestrated employee participation. The cascading change process is found to build participation, transparency, trust, and commitment to the change among employees and managers. In turn, this ensures that implementation occurs without problems.
\end{abstract}

Keywords: Planned and emergent change; employee participation; change leadership

MAD statement: Organizational change often fails at delivering the envisioned results. This paper proposes a 'model of cascading change' that combines planned and emergent change management approaches to orchestrate change. In this model top management defines the scope of the change process but leaves the analysis, diagnosis, and solution 
development to the employees through a series of workshops. A structured handover between workshops ensures that knowledge and solutions are transferred transparently. During a final culminating workshop, all solutions are qualified across professional groups and presented to the top management, who subsequently implement them. The model generates employee engagement and ease of implementation. 


\section{Introduction}

Understanding how and why organizational changes succeed is of paramount importance because most changes do not deliver the expected results (Hughes, 2011). This fact is mirrored in hospitals, where changes often produce more problems than they solve, leading to widespread change skepticism among health care professionals (Ackroyd, Kirkpatrick, \& Walker, 2007). Internally, hospitals face challenging change management processes (Heldal, 2015; Ramanujam \& Rousseau, 2006) because the managerial logics of change and efficiency clash with strong professional identities and decision-making autonomy regarding how to work and transform inputs into care outputs (Garman, Leach, \& Spector, 2006; Mintzberg \& Glouberman, 2001; Powell \& Davies, 2012; Dopson, Fitzgerald, \& Ferlie, 2008; Strauss, Fagerhaugh, Suczek, \& Wiener, 1997; Scott, Ruef, Caronna, \& Mendel, 2000). Yet external pressures require hospitals to change care delivery to meet changing patient demands - for example, when comorbidity is pressing (Barnett et al., 2012) and outpatient visits can replace inpatient stays (American Hospital Association, 2019) - and fulfill public demands for cost-efficient, safe, and high-quality care (Institute of Medicine, 2013). Given these internal and external characteristics, it is paramount to find ways to successfully manage change in hospitals.

The organizational change literature routinely attributes organizational change success to one of two contrasting perspectives (Beer \& Nohria, 2000; Palmer, Akin, \& Dunford, 2009; Van De Ven, Poole, \& Poole, 1995; Weick \& Quinn, 1999): either as a planned (Al-Haddad \& Kotnour, 2015; Kotter, 1995; Sirkin, Keenan, \& Jackson, 2005) or emergent process (Julia Battilana \& Casciaro, 2013; Burnes, 2004a). Both the planned and emergent perspectives deal with the aspect of the change process that 'bring about change' (By, 2005) but differ by belonging to top-down and bottom-up change management logics, respectively. Given the unique internal characteristics of how 
hospitals work (Dopson et al., 2008), on the one hand, this implies that change initiatives initiated and executed in a top-down manner are unlikely to succeed (J. F. Nielsen \& Riiskjær, 2013; K. Nielsen, 2013). On the other hand, even though bottom-up change processes appear critical for hospital change processes, this may run counter to managers' affinity for 'making change' (Palmer et al., 2009).

Although these two contrasting change perspectives are important for understanding change processes in practice, theoretically, they largely operate in parallel, thereby restricting the current understanding of how change unfolds in practice (Heyden, Fourné, Koene, Werkman, \& Ansari, 2016) and over time (Bartunek \& Woodman, 2015). This paper connects to the ongoing discussions about the nature of the change process that call for a more nuanced and detailed understanding of the dynamics of change processes (Laine \& Kuoppakangas, 2015; Preget, 2013). By reconciling the planned and emergent approaches toward change management, the aim of this paper is to answer the following question: How do the planned, formal aspects of change management interact with the emergent, informal aspects in bringing about organizational change?

Using a case study approach (Yin, 2009), which is capable of studying the process dimension of change (Pettigrew, 1988), we unravel the temporal dynamics of a department-wide change project within a large world-leading cardiology department in Denmark, thereby allowing us to answer the call for developing novel integrative change strategies (Laine \& Kuoppakangas, 2015). This particular hospital case is insightful because the change project succeeded despite facing obstacles such as doctors 'running the show', poor interprofessional collaboration, and opposition toward the department's management, as documented by a pre-project annual work environment survey in 2012 . Contrary to most change projects in hospitals (Ackroyd et al., 2007), our post-project evidence shows successful implementation of 30 out of 31 solutions, a statistically 
significant $(\mathrm{p}<0.05)$ increase in relational coordination (see Figure 1) that indicates better work collaboration (c.f., Gittell, 2002) and a small increase in productivity (see Figure 2) (data available from the first author upon request).

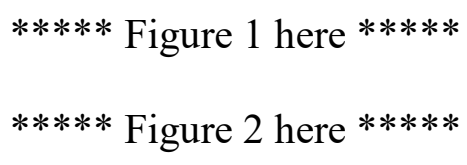

For this change to succeed, our post-project analysis of the change management process shows that the change unfolded through what we name a 'model of cascading change' a change model that reconciles the planned formal and emergent informal perspectives on change processes with a strong basis in employee participation and engagement. We attribute these improvements to the employee-driven cascade structure, which ensures transparency in the change process and employee commitment to the change, because no other major changes in the organizational context (e.g., budget cuts or management changes) took place during the change process.

The model of cascading change refers to the finding that change activities start in a small group and spread to more and larger teams, ending with all employees participating and being engaged. Each of the different teams in the department (the management team, team leaders, surgical teams, workshop teams, etc.) goes through the Lewinian processes of unfreeze, move, and refreeze. The cascade of changes occurs in the succession of the unfreeze and move stages, which are initiated by participation in project workshops. The refreeze stage, however, occurs only just before the implementation stage and happens simultaneously for all members involved. The cascade structure creates change transparency for the employees because the results from each workshop are handed over to the next workshop, where the results are used as an input for their work that they 
subsequently hand over to the next workshop. Alongside the cascade structure runs a process of escalating commitment and employee participation whereby more and more employees become successively engaged in the change process. This process of escalation allows each work group to follow the reasoning and conclusions of the previous group, in turn facilitating the ability to acknowledge the situation and agree upon the solutions. The model of cascading change is orchestrated by the TMT because they set the direction and scope the project, but they do not interfere in the employee-driven diagnosis of problems and development of solutions. Moreover, top management accepts and agrees to implement the proposed changes, and team leaders and employees agree to support the subsequent implementation process, thereby forming what Rousseau (1989) conceptualizes as a psychological contract of reciprocal obligation found to create project commitment and employee engagement (Van Elst \& Meurs, 2016).

\section{Theoretical background}

\section{Change management from a planned and formal understanding}

Planned episodic change tends to be infrequent, slower because of its wide scope, less complete because it is seldom fully implemented, more strategic in its content, and more deliberate and formal (Burnes, 2004a; Weick \& Quinn, 1999). Planned change is intentional, it is driven by top-down control, and top management is responsible for the change process and acts as a controller for who is leading the change process (Bamford \& Forrester, 2003; By, 2005). The purpose of the change process is to discard old behavior, adapt new behavior, and move the organization from one state to another (By, 2005). The change process is slow, infrequent, linear with well-defined stages, and is governed by rationality and determinism; here, the external environment is assumed to be stable and predictable. 
An influential framework for understanding planned change processes is Lewin's (1947) three-phase change model of unfreeze, move, and refreeze, all of which occur at the group level (Al-Haddad \& Kotnour, 2015). The unfreeze phase involves an opening, a spark, and the idea that it may be possible to change the current situation. The initial thought may be from a single individual, but it must spread to the group to have an effect. The move stage concerns the active and deliberate processes of analyzing, understanding, and developing alternatives to the current situation. A move occurs when a group develops solutions to the problems found in the current situation. Refreeze involves the deliberate selection of a better alternative to the current situation - a new desired situation. Both the move and refreeze stages must not be mistaken for making and concretely implementing the actual change; that is, a move means designing the desired new situation, and a refreeze means the conceptual acceptance of the desired new situation.

To transition through the unfreeze, move, and refreeze phases, the planned formal change literature asserts that change can be successfully achieved through means such as planning and staffing (Kotter, 1995), formal change-agent skills (Ford, Ford, \& D'Amelio, 2008), a pre-change project assessment (Sirkin et al., 2005), and mapping of the socio-political context (Cobb, 1986; DeLuca, 1984). Formal power (Buchanan \& Badham, 1999) and human capital bargaining power (Brown, Gianiodis, Santoro, \& Brown, 2015) are also important from a top-down perspective. Empirically, however, Ashburner, Ferlie, and Fitzgerald (1996), who study macro-level changes in the National Health Service in England, question the rather linear and rigid notion of change because both planned and unplanned changes happen at the same time. Similarly, radical topdown change strategies are severely hampered in professionalized public service organizations such as hospitals because of dominating health care professions (McNulty \& Ferlie, 2004). The planned approach to change has been critiqued for being too linear 
and static (Kanter, Stein, \& Jick, 1992), assuming that organizations operate in stable environments (Bamford \& Forrester, 2003), and that change tends to be incremental and small scale in nature (Burnes, 2004a).

\section{Change management from an informal and emergent understanding}

Emergent continuous change, in contrast to the typical planned and formal understanding, is frequent, evolving, and cumulative (Burnes, 2004a). This type of change is faster because of its narrower (everyday) scope, is often less deliberate, is informal, and is closer to the front line, and is less disruptive because it involves first-order changes, thereby extending the present in incremental ways (A. D. Meyer, Goes, \& Brooks, 1993; Tushman \& Romanelli, 1985; Weick \& Quinn, 1999). Bottom-up informal drivers of change include personal networks (Julie Battilana, Dimitriadis, \& Gargiulo, 2012), change readiness and resistance (Ford \& Ford, 2009; Ford et al., 2008; Piderit, 2000; Rafferty, Jimmieson, \& Armenakis, 2013), and organizational culture (Cameron \& Quinn, 2006; Chatman \& Eunyoung Cha, 2003). Socio-psychological underpinnings (Dutton, Ashford, Neill, \& Lawrence, 2001), such as psychological safety (Edmondson, 1999), sense making (Maitlis \& Sonenshein, 2010), and learning anxiety (Schein, 2004), are as equally important as the communicative aspects are, including change discourse (Ford \& Ford, 1995; Heracleous \& Barrett, 2001), narratives (Sonenshein \& Sonenshein, 2016), and continuous interpretations (Isabella, 1990). Emergent change is evolving and is driven by bottom-up action; in addition, responsibility is devolved and delegated, and top management facilitates the change process to create change readiness within the organization (Bamford \& Forrester, 2003; By, 2005). The focus of the change process is understanding the need for and complexity of the change by adopting a contingency approach (By, 2005). The change process is fast, continuous, and an open-ended learning process characterized by adaptation and experimentation. 
Regarding the emergent informal and bottom-up aspects of change management in hospitals, Lapointe and Rivard (2005) find that the bottom-up process by which group resistance behaviors emerge from individual behaviors is not the same in early versus late IT implementations in hospitals. For early implementations, the emergence process is one of compilation and is described as a combination of independent individual behaviors. In the later stages of implementation, if the group-level initial conditions have become active, the emergence process is one of composition, which can be described as the convergence of individual behaviors. Dutton et al. (2001) show the importance of various issue-selling moves (e.g., packaging, involvement, and timing) for successfully shaping change from below by directing the attention of top management. Regarding resistance behaviors in hospital change, Shaw (1997) finds that for hospital to succeed with change, it is important to engage in the 'shadow system': 'the complex web of interactions in which social, covert political and psycho-dynamic systems coexist in tension with the legitimate system' (p. 235). Relatedly, in studying policy implementations in hospitals, McDermott, Fitzgerald, and Buchanan (2013) show 'how public sector change recipients can avoid, abstain, adopt, adapt or add to policy agendas' (p. 94). Brown et al. (2015) come to a similar conclusion by identifying how physicians' power in hospitals manifests itself through human capital bargaining power.

\section{An integrated understanding of change management driven by employee participation and psychological contracting}

Although both change perspectives are illustrative and have distinctive features, failing to integrate a parallel understanding restricts the understanding of how actual change unfolds (Heyden et al., 2016). Orlikowski (1996) finds that change processes unfold as a mix of deliberate (planned) and emergent changes in work practices, thereby indicating that both coexist and interact in organizational change processes. Even though both 
represent different change perspectives, they may be integrated through sequencing that creates a 'rhythm of change', thereby addressing the temporal elements of the change process (Huy, 2001; Huy \& Mintzberg, 2003) or via a combined approach (Beer \& Nohria, 2000). In a similar vein, Van de Ven et al. (1995) highlight the coexistence of up to four 'change motors': dialectic, life cycle, teleology, and evolutionary. Using their theoretical framework, managers may initiate a change process in a top-down manner, but for the change process to succeed, it is necessary to encompass bottom-up processes so that the members of the organization can contribute alongside other lateral change processes driven by, for example, external consultants or internal staff functions. Furthermore, Burnes' (2004a) case study of a large European-based construction service company shows that planned and emergent change processes coexist. Bamford and Forrester (2003) similarly find that the responsibility for driving the change processes often shifts among the different management levels in the organization.

Heyden et al. (2016) extend the discussion on human agency by studying different combinations of top-down and bottom-up roles (change initiator, executer, or both), finding that the most effective change strategy is also the least used, that is, change initiation by middle managers and change execution by top management. For these reasons, we extend the integrated perspective on change management by stressing that no matter what the driving forces are and how the change process is initiated and managed (i.e., planned or emergent; Laine \& Kuoppakangas, 2015), employee participation is a key success factor because 'only by gaining the commitment of all those concerned, through their full involvement in the change process, would change be successful' (Burnes, 2004b, p. 995) - a claim that has been supported empirically (Fuchs \& Prouska, 2014; Lines, 2004). The enabling bureaucracy model of hospitals similarly stresses participation and involvement in the design and change phases (Adler \& Borys, 1996; 
Adler, Heckscher, \& Prusak, 2011). Participation is important, for example, for building trust in the change process and for creating trust between management and employees (Lines, 2005; Lines, Selart, Espedal, \& Johansen, 2005). Furthermore, participation reduces organizational change resistance through improved information sharing (Kotter \& Schlesinger, 2008), decision making (Kim \& Mauborgne, 1998), and organizational commitment (Lines, 2004).

In a factory context, the seminal work of Coch and French (1948) demonstrated that resistance to change could be overcome by including workers in the design of the changes; a positive effect was demonstrated for both direct involvement and representative involvement although this was higher for direct involvement. Participation is a pillar of the 'commitment' strategy (Walton, 1985), where management involves employees in job design, replacing top-down controls with mutual influence and coordination based on shared goals. Commitment may also be formed through a psychological contract (Corder \& Ronnie, 2018; Rousseau, 1989), where an individual has a belief regarding a reciprocal exchange agreement. Indeed, emergent change processes empower employees to participate in a change process and contribute to formulating changes, which in turn form expectations that these changes will indeed be implemented. It is further expected that management will champion the proposed changes and not modify them to fit their own agenda. Such modification would constitute a breach of the psychological contract and as a result spark resistance to change among employees who have developed psychological ownership (Cocieru, Lyle, Hindman, \& McDonald, 2019) through their participation. In episodic top-down change processes, management form expectations of the change they have initiated and expect employees to change. A prerequisite, however, is openness, good faith, and fair dealings (Rousseau, 1989) in the 
change process, which may be difficult in planned change because management imposes their will and decides the direction of the change.

Participation and involvement in the change process create an organizational environment that is conducive to successful change. However, little research has been undertaken on how to orchestrate participation and concretely balance the planned and emergent driving forces within the change process.

\section{Methods}

To study how change can be orchestrated to succeed, we present the findings from a single case study of a successful change project at a leading cardiology department in Denmark. We employed a quasi-experimental pretest-posttest design (Grant \& Wall, 2009) because the department was about to embark on a change project and because the first author (KE) was approached for advice and was serving as consultant during the planning, diagnosis, and development of solutions but was not involved in implementation. The nature of the quasi-experiment is a real-life setting constituted by the change project in the cardiology department. The independent variable is the model of cascading change, and the outcomes are the changes in relational coordination and implementation of the developed solutions, which were measured both pre- and post-implementation. The experiment comprised three phases: 1) pre-implementation, including project planning, diagnosis, and the development of solutions, 2) implementation, and 3) the post-implementation, where the project was completed and staff members were using the implemented changes.

Although quasi-experimental in nature, the research design also drew on the organizational development tradition of action research (Coghlan, 2011; Coughlan \& Coghlan, 2002), which is concerned with studying organizational change carried out in close collaboration between the researcher and practitioners by going through a process 
of diagnosing, planning, acting, and evaluating. To that end, the study focused on reallife issues relevant for both theory and practice, which was achieved through integrating systematic research, reflection, and scientific knowledge (Coughlan, Draaijer, Godsell, \& Boer, 2016; Shani, Mohrman, Pasmore, Stymne, \& Adler, 2007).

The first author had the role of an action researcher in his capacity as an external project consultant and, at the same time, a university researcher. This allowed him to influence the change process and stimulate a different and deeper level of reflection among the project participants (Eady, Drew, \& Smith, 2015). Toward the same end, quantitative data was used to inform observations and engage participants in the process (Marti, 2016).

The action research aspect was pronounced in the design of the project, where KE and the resident consultant found the initial top-down approach by the department's top management team (TMT) as not likely to succeed. This was because of the high professional autonomy and strong opposition toward the TMT. Although this prediction could not be tested, it was debated with the TMT and resulted in a radically different project design. Hence, during the post-implementation period, an analysis of these two varying approaches became the model of cascading change presented in this paper.

\section{Case overview: A leading cardiology department in Denmark}

In autumn 2011, following a merger with a similar department from a nearby hospital, staff grew by $40 \%$ at the cardiology department rising to 150 employees but without increasing the physical size of the department. Production also grew by $40 \%$, meaning there were approximately 1,860 heart procedures, 1,200 lung procedures, and 2,200 scopic procedures per year. The merged department kept a traditional functional structure,

where the occupational groups had their own functional manager. The functional managers reported to departmental management, and all managers (except for the clinical 
director) worked part time on the floor. Postmerger surveys of staff wellbeing conducted by the department indicated poor working relations among staff members. At the same time, the management felt that production (surgery) could be planned and executed more efficiently. To counter the problems of this merged department, the management decided to initiate a project with the help of an internal hospital consultant and an external consultant (KE). The two-year project started in January 2013 and ended in March 2015. Table 1 shows an overview of major events - a detailed analysis is presented in the results section. KE participated in the project from January 2013 to October 2013, when implementation began and the merged department managed all implementation activities by itself.

\footnotetext{
******Insert Table 1 here - Overview of major events*****
}

\section{Data and data analysis}

Covering the period before the change process was initiated, during the change and implementation period, and after the changes had been implemented, a large body of data was collected. This allowed us to follow the change process through all phases, including the evaluation of the change outcome.

To understand the pre-change situation, we relied on three different types of data. First, to obtain insights into how the department planned, organized, and executed surgery, seven randomly selected surgical procedures were observed and recorded as research notes by KE and two internal lean consultants. Second, to understand the history of the department and identify changes in work and wellbeing, four effect modifier assessment (EMA) workshops (Edwards \& Winkel, 2018) with a full surgical team and two EMA workshops with team leaders were conducted and transcribed. In an EMA workshop, the participants would first write down important events, which were then 
placed on a timeline and discussed. Each workshop lasted two hours and resulted in 210 pages of transcriptions, with 282 events being written down by the participants. Third, individual insights and experiences from daily work were collected using work diaries written by the employees. The work diaries were distributed $(n=108)$ in the lunchroom and collected two weeks later $(n=48)$; the work diaries contained a total of 402 personal accounts of work frustrations. The personal accounts were transcribed ( 24 pages) and grouped into 34 topics. To follow the development of the solutions, KE participated in three A3 workshops, each with a full surgical team, resulting in 31 written A3 problem descriptions and solutions.

**** Insert Table 2 here **** - List of changes and their status

To track the change process, we collected project minutes, research notes, and emails from the TMT and steering group meetings from January 2013 through October 2013. Furthermore, project plans, meeting minutes, and status bulletins related to the implementation phase covering the period from October 2013 through March 2015 were retrieved from the chief secretary in December 2016. Finally, production data (heart and lung procedures) from 2010 through 2015 were collected from the planning system at the cardiology department. We undertook follow-up interviews in December 2016 with the head surgeon (90 $\mathrm{min})$, the head nurse (45 $\mathrm{min})$, and a senior anesthesiologist (30 $\mathrm{min})$ to identify any positive or negative influences (such as a change in management) on the change project during the implementation period, in which the authors did not participate.

The data analysis was guided by a central question: What made the project a success? The hypothesis was that the principles underlying the project's design (the sequence and type of events) were important to the change success. Specifically, we 
analyzed the data by creating a timeline of events and formulating a narrative (cf. results section) devoid of theoretical constructs. The narrative was pieced together from the process data (Langley, 1999) collected during the project as participant observer research notes and minutes from the steering group meetings. The narrative was then analyzed using the theoretical constructs presented in the theory chapter to explain the observed patterns and form a theoretical and internally logical explanation for the narrative. The theoretical explanation was refined through many iterations.

\section{Results}

\section{A dire situation}

In the autumn of 2012, the TMT at the cardiology department became decisively aware of poor staff wellbeing. The TMT's perception of the declining productivity and the underutilization of operating rooms was that surgeries and procedures required better planning for more efficient execution. One central reason behind these operational issues was the 2011 merger, where the thorax surgical clinic and the anesthesiology clinic from the nearby hospital merged with the cardiology department. Overnight, 750 yearly heart procedures, along with their accompanying employees, relocated to the existing facilities at the cardiology department.

The 2011 merger did not go smoothly because of limited change management. Indicative of the management style at the cardiology department, it was de described that the TMT simply added the incoming staff to the existing roster and expected them to work as if nothing had happened. There was significant tension between the original staff and the newcomers. For example, being a leading cardiology department made the original staff at cardiology department feel superior - something they made the incoming staff aware of. Even with changes in the TMT and the limited physical size of the clinic 
amplifying these tensions, no attempts were made to improve the situation, thus negatively impacting staff wellbeing.

\section{The TMT's realization, disagreement, and compromise}

Staff dissatisfaction, poor staff wellbeing, declining productivity, and the inefficient use of resources ultimately made the TMT initiate a change process to improve the department's dire situation. In mid-January 2013, the TMT invited an in-house lean consultant from the hospital and an external research consultant who specialized in wellbeing and relational coordination (first author, KE) to a meeting to discuss approaches for resolving the situation. The two consultants represented competing change approaches, which also reflected tension within the TMT. The 'lean group', the internal consultant and two from the TMT, believed that lean principles would solve the underutilization issue and that poor wellbeing stemming from tension among the staff had its roots in a lack of surgical competence. In contrast, the 'relational coordination group', the external consultant (KE) and the remaining two from the TMT, viewed the poor wellbeing and deteriorating collaboration as resulting from poor operating processes, low social capital, and poor management. This group feared that too strict a lean approach would only amplify tensions. From January 2013 through March 2013, the TMT and the consultants discussed possible project approaches. As these meetings unfolded, the tension between the two groups became increasingly clear, with no common understanding of a cause and solution to the problem. Besides the TMT lacking consensus, the two different approaches highlighted that the underlying root cause was not understood. A compromise between the two groups was to widen the project scope to include an initial in-depth diagnosis and to let staff identify and develop solutions through lean A3 workshops. 


\section{A participatory approach for diagnosing the situation}

In mid-May 2013, the staff and managers embarked on a participatory process to identify problems and solutions. Because the team leaders had daily contact with the staff, it was imperative for the TMT and consultants to get them to commit to the project. The TMT thus called for a meeting where team leaders could voice their concerns and propose changes to the project proposal. Afterwards, the team leaders agreed to be part of the project steering group and support the project. At the end of May 2013, the TMT announced the project entitled 'Quality, collaboration, activity and coordination in the operating theatre'. Because of the tensions between the management and staff, the consultants carefully coordinated announcing the project so that everybody received the information simultaneously. In practice, the team leaders presented the project at the short weekly Thursday morning meeting that was held for all teams in the cardiology department, and at that time, all staff also received an email presenting and explaining the project.

From early to mid-June 2013, the consultants began identifying problems using EMA workshops (Edwards \& Winkel, 2018), where KE facilitated the group discussions. The EMA workshops identified seven main issues causing frustration among staff: management (e.g., TMT being 'top-down', 'dictator-like', and 'old-fashioned'), collaboration (e.g., tensions and conflicts between the old guard and the newcomers), the physical layout (lack of space and a disorderly working space), organizational issues (e.g., disputes over professional boundaries), external collaboration (e.g., strained collaboration with the intensive care unit), culture (e.g., different opinions about how to work), and rebuilding (e.g., needing new ventilation).

In mid-June 2013, the consultants observed the cardiology department during two-day observations of the surgery unit to learn about work practices, relations, and 
tensions. The observations revealed a harsh culture where bullying by the operating surgeon was unopposed and quietly accepted, as witnessed by surgeons reacting badly if the support staff were inattentive. Also, in mid-June 2013, the consultants handed out a work diary to all staff members so that they could write personal accounts of their daily frustrations and the practices that created frustration that prevented them from doing their job. Forty-eight staff members wrote their frustrations (402 notes in total), for example, 'Invisible management, top-down - old-fashioned authoritarian management - more stick than carrot', which, per agreement, subsequently were emailed to all staff to ensure transparency about these daily frustrations.

\section{Agreeing on the diagnosis and change process}

Using the results from the observations, EMA workshops and notes grouped into 34 topics from work diaries, in June 2013, the steering group and consultants decided that the project should focus on four themes: equipment and physical space; coordination and planning; collaboration; and management. For each of the three first themes, the steering group agreed on organizing a two-day A3-workshop (Jimmerson, 2007), whereas the TMT and team leaders were to deal with the management theme in two separate workshops. By the end of June 2013, the steering group informed all staff about the four themes in an email and during one of the weekly Thursday morning meetings. The steering group had prepared and coordinated the content of both to ensure that everybody received the same information. Shortly after announcing the project's themes, the project went idle for five weeks between early July 2013 and mid-August 2013 because of summer vacation. By mid-august workshop participants received a personal mail inviting them to the workshop, explaining the context, process so far, scope and how the workshop results were to be used, 


\section{Developing solutions}

In late-August 2013 after returning from the summer vacation, the consultants held the A3 workshops concerning the three first themes: two in one week and the third the week after. Each A3 workshop had a full surgical team of six people with all professions present, with a total of 18 employees involved. Importantly, the steering group and consultants had handpicked the participants who were personally and professionally respected among the staff and known to be outspoken about the specific theme. Each A3 workshop followed the same six-step structure. First, the participants were welcomed and then informed about the project, project plan, and reason for their participation. Second, the participants were informed about the data that had been collected and how it had been interpreted and developed into themes. Third, the internal lean consultant gave a brief lecture on the importance of designing a system that would provide the desired results, stressing that 'every system is perfectly designed to get the results it gets' (Batalden, 2019). Fourth, a Whole Brain ${ }^{\circledR}$ (Hermann Global, 2019) test was used as an ice-breaker exercise to illustrate personal differences and highlight that everyone was equal and had an equally important input into the process. Fifth, the workshop participants then started discussing the particular theme assigned to that specific workshop. Sixth, the consultants turned the group discussion into a regular brainstorming session and started solving problems using the A3 methodology. The first five steps took a couple of hours, leaving the remainder of the two days for focusing on problem solving. The results from the previous activities were available to the participants, and transcribed notes from the work diaries and results from earlier EMA workshops were printed and available in the room. The participants frequently used the results from previous activities to be inspired by the notes and statements underlying the workshop theme. 
The results from the three workshops were 31 A3 solutions, with each one containing a description of the problem and current situation, an analysis of the underlying causes, a solution about what to do, an action plan including the names of those responsible for each decision item, and an evaluation measure to determine when the problem had been solved. Regarding the latter, the workshop participants formulated an accompanying question to measure the extent of each problem. The questions were to be used in the staff questionnaire distributed pre- and postimplementation to measure the general perception toward the identified problems and to ensure that they were not idiosyncratic to the workshop participants who had first identified the problem.

In late August 2013, the steering group met to review the A3 solutions and discuss the staff-formulated questionnaire. Although the TMT was happy with the 31 solutions, it was unimpressed with the wording of the questions and proposed alternative formulations. The consultants strongly opposed changing the wording by arguing that the agreement with the workshop participants was to use their wording, regardless of quality, and that it risked portraying the steering group as manipulative. The TMT finally agreed, and the steering group emailed the survey to all staff members. This was coordinated through team meetings where the team leaders encouraged everyone to complete the questionnaire. The results from the questionnaire were to be used at the final conference that would present the results of the project.

\section{Culmination}

In late-September 2013, the project culminated in three major workshops. Because surgery requires 24-hour staffing, it was not possible to have a single workshop for all the employees, so three identical workshops, each with one-third of the staff, were held within a one-week period. Participation was mandatory, and the workshops started just after the day shift ended (at 3 p.m.) and lasted for three hours. At each culmination 
workshop, the TMT welcomed the participants by expressing how it was important for everybody to contribute and offer their perspectives and then the TMT left the workshop. The TMT did not stay to ensure that the low levels of trust in the management team did not affect the participants and the process. Next and to provide a foundation for the subsequent staff discussions and work, participants from the A3 workshops presented their 31 solutions and the lean consultant presented the results from the staff questionnaire, which showed that most agreed on the proposed solutions.

Then, the employees formed groups depending on the problems they wanted to discuss and influence. This process was self-organizing, and the employees switched problems and groups during the session depending in personal preference. The discussions, however, followed a fixed structure to ensure that each group discussed each element on the A3 problem sheets and added post-it notes with their comments (changes, rebukes, or confirmations).

At the end of each culmination workshop, the TMT returned, and the results of the discussions were presented. The TMT had decided beforehand that it would immediately pursue 29 of the 31 solutions unless the workshops showed strong opposition. The two remaining suggestions were too expensive and were completed later in 2015. Finally, the consultants collected and transcribed the A3 sheets that had been commented on. In late September, the consultants wrote up the A3 comments, emailed them to all staff members for reference and transparency, and discussed them with the steering group. The consolidation did not result in major changes to the 31 original A3 problem sheets. Most of the staff members' comments concerned the problem description and analysis, hence providing a more nuanced understanding and some comments that could be added to the solutions. 


\section{Successful implementation of the solutions}

Shortly after the three culmination workshops and to ensure transparency, the steering group informed all staff members about its detailed implementation plan by emailing the process plan. The progress report was placed on the wall in the operating ward and was updated every week to ensure full transparency. The implementation process began in mid-October 2013, implementing only a few solutions at a time and making sure each solution received sufficient attention and focus. This allowed the changes to stabilize before proceeding to the next proposed solution. To increase the focus on implementation, the TMT decided to minimize the number of other internal projects and shielded the cardiology department from outside interference (e.g., projects from the central administration). To help the implementations move forward, the steering group assigned project responsibility to two team leaders who reported to the steering group. The consultants did not participate in the implementation phase. As soon as the implementation of a solution started, changed status (e.g., awaiting tender, ordered, etc.), or was finished, the team leaders reported it to the steering group, and a secretary updated the process plans. The steering group met monthly to monitor implementation progress and decide on which initiative to work on next. Implementation was completed in spring 2015.

\section{Discussion}

\section{A model of cascading change: theoretical implications}

By combining the insights from the empirical narrative of the change process at the cardiology department with theoretical insights about organizational change, we develop what we call 'a model of cascading change' (see Figure 3). This model contrasts the oftenreported change approaches where management defines the goal and new situation, 
thereby limiting the opportunities the rest of the organization's members have to participate in envisioning the new situation and in the diagnostical and analytical processes for how to get there. The model of cascading change has three central characteristics: 1) the cascading change process with structured transparent handovers; 2) a Lewinian process integrating the individual, group, and organizational levels; and 3) an orchestrated change process where top management define the scope of the change process and champion implementation in the end, but leave analysis, diagnosis, and solution development to the employees through a series of workshops.

\footnotetext{
$* * * * *$ Insert Figure 3 here $* * * * *$
}

\section{Cascading change and transparent handovers}

The concept of cascading change refers to the finding that over time, an increasing number of employees become engaged in the change process though their participation in workshops that are tasked with diagnosing, analyzing, and developing solutions. For the cascading process to function, structured handovers between workshops are instrumental because they allow the handover of results and responsibility for designing the activities, analyzing and identifying problems, and developing solutions for the identified problems. Furthermore, the handovers are transparent in the sense that it is a written document that allows the next workshop to continue the work of the previous one. The handovers, therefore, also entail codification of the knowledge created so far, ensuring transparency, because the document in the handover is made available for all to read, not just the next workshop.

The cascade is a series of handovers involving more and more employees. Examples of handovers in this case are the TMT framing the project and handing it over 
to the steering group responsible for overall planning. The steering group then hands over the task of analyzing the organizational problems to the six focus groups. The handover for participants in the A3 workshops was a detailed one-page email inviting the participants to take part in the A3 workshop and that described the status of the project and the overall theme of the A3 workshop. The theme, derived from an analysis of the employee dairies by the steering group and consultants, was not a detailed description but rather a direction for the workshop. The email also described how the results would be used and presented at the culmination workshops but not which results were expected. Discussing and commenting on the solutions are handed over to all staff members participating in the culmination workshops and qualified across professional groups. Finally, overall responsibility for the implementation was handed back to the TMT, who oversaw the actual implementation of the agreed-upon solutions.

\section{Lewinian process of unfreezing, moving, and refreezing}

We find three distinct phases of realizing, formulating, and deciding what to change. These phases mirror the Lewinian processes of unfreezing, moving, and refreezing, but at escalating organizational levels, that is, individual, group (in our case the A3 workshops), and department (in our case the culmination workshops). Each handover initiates the Lewinian processes of unfreeze, move, and refreeze. Unfreeze happens when a handover is received by an employee, which also implies that unfreeze is an individual process where a person perceives an opening for organizational change. Move is a group process that takes place in the A3 workshops, where the participants analyze and develop solutions. Whereas the unfreeze and individual perception of opening are idiosyncratic, the move process is collective and only at the group level as A3 workshop participants discuss and move together to analyze and develop solutions. 
Refreeze is the collective decision to implement a solution that must be done in a forum such as the culmination workshops where most, if not all, of the employees are present. Each handover and workshop trigger an individual unfreeze and group move, but the organizational refreeze must wait until the culmination workshops. This ensures employee participation and transparency when moving toward the decision of the proposed changes.

The Lewinian processes of unfreeze, move, and refreeze for the change project are illustrated in Figure 1 above as lines starting at different points but all ending at the same point - the culmination workshops. The lines start out flat, illustrating that the unfreeze stage begins with the handover for a workshop. The lines slope quickly downwards through the move phase, illustrating that it happens rather quickly (e.g., at the A3 workshops). Because no final decisions are made at the workshops, the line continues and ends with the culmination workshops.

The handover initiates the unfreeze stage, and as an example, the invitation to participate in the A3 workshop on equipment and physical space immediately signals that there are problems regarding equipment and physical space. This initiates the unfreeze phase for the individual because the participants are asked to discuss problems and develop solutions, thereby creating a spark and interest in changing the current situation. During the workshops, the participants move as they analyze, discuss, and propose solutions. The move happens because the participants are actively engaged in developing solutions that they find relevant and interesting. Compared with the unfreeze stage that opens the possibility for change, the move stage represents a change in perception of what the problems are and how they can be solved. 
Orchestrating participation and commitment to create transparency and ease implementation

The cascading model is orchestrated in the sense that it is an intentionally designed process of escalating commitment where more and more employees successively participate in the change process, leading to increased commitment to the solutions. The orchestrated process is foundational because it guides the overall plan of the change process. It is also a deliberate choice by the management to commit to a change process that is transparent and engages employees in the diagnostic and analytical processes, as well as the development of solutions. When orchestrating, top management does not define the goal but instead sets a direction by formulating the general themes and general scope of possible changes that management will accommodate. The scope must be sufficiently broad to provide leeway for the employees to develop solutions. The data collected from observation, EMA-workshops and topics from work diaries serve as the foundation for defining themes and setting the scope as was done in this case. The workshop invitations specified the scope by mentioning example topics.

Information-sharing and the resulting transparency are similarly important to the cascading model of change because it allows all employees, not just management, to follow the process. The initial project description sent by the TMT explains the purpose and need for change. The A3 workshops use the A3 format to describe the problem, analyze, explain solutions, and describe the implementation process, which in turn was easy to communicate and distribute to all employees. This transparency allows employees to establish a direct connection between the project description and themes from the TMT and the proposed changes from each of the three A3 workshops.

Information sharing also facilitates accountability because the minutes and results from the workshops are freely available, and it is not possible for special interest groups or the TMT to circumvent the process and promote their preferred solutions. Furthermore, 
information sharing, and participation instills the staff members' trust in the change process, which was important given the initial low level of trust in management. Indeed, the TMT was tempted to comment and modify the changes proposed at the A3 workshops. The consultants urged restraint and trust in the process and argued that any modifications would go against the orchestrated process where top management sets the direction and takes ownership for the implementation but leaves the analysis, diagnosis, and solution development to the employees through a series of workshops.

\section{Successful implementation}

The successful implementation of the 31 solutions is considered a result of the change process - what we subsequently named a 'cascading model of change' - in which employees and the TMT had discussed and, through the culmination workshops, explicitly agreed to implement the proposed changes. This forms mutual expectations and lays the groundwork for a psychological contract where the TMT expects that the changes are desired and that they will not be resisted, while the employees expect the TMT to follow the implementation plan. The managed change process focuses on implementing the proposed changes as outlined by the employees in the A3 problem descriptions. Those responsible for the particular change provide continuous progress updates to the TMT and the employees so that the progress and status is available for all to see. The changes are then documented and reported to all staff in the form of progress reports. Displaying the progress reports was a deliberate and explicit decision by the TMT to build trust through transparency. Making these reports are important because the management becomes the steward of changes proposed by employees and must demonstrate implementation.

However, even though the solutions are developed by the employees in a participatory manner, the implementation process must still be managed by the TMT. 
First, some of the changes require that resources are committed to implement the change and these resources are typically controlled by top management. Second, it is necessary to implement the changes while maintaining daily operations, and therefore, it is important to distribute and sequence implementations over a suitable time period to avoid capacity problems and maintain production (Meyer \& Stensaker, 2006).

\section{The cascading model of change vis-à-vis other change models}

The cascading model of change forms an emergent change process, but contrary to Burnes (2004a), it is not a completely emergent change process because the TMT sets the overall scope for the change, identifies the overall themes, and orchestrates the process (A3 workshops, group interviews, etc.), but the employees are free to develop solutions and decide the content of the change. Moreover, decisions on what to change are made at the end when all the employees converge during the culmination workshops and then refreeze. In relation to the framework by Heyden et al. (2016), we find that change is initiated by top management and executed by middle managers who are charged with implementation. The TMT, however, only specifies the process and direction, not the problem and what to change as in planned change. This is where planned and emergent change comes together.

Employee participation is a key factor for gaining commitment, but the literature is divided about how fully the change should be planned before those who will be influenced by the change are invited to participate (Laine \& Kuoppakangas, 2015). Our study suggests that employees should not merely participate but also be responsible for developing solutions. The overall change process, however, should be orchestrated by the TMT. The Lewinian processes of change we identified extend the original understanding of unfreeze, move, and refreeze from being a process of social change taking place in a group (Cummings, Bridgman, \& Brown, 2016) because we find that the three distinct 
phases of realizing, formulating, and deciding what to change mirror those Lewinian processes, but at escalating organizational levels, respectively, the individual, group, and department level.

Whereas Shaw (1997) found that the 'shadow system' has to be engaged to succeed, we find that the participatory process of information sharing and transparency disable the 'shadow system', engages employees, and circumvents blocks to implementation. The TMT's promise to follow the solutions developed by the employees lays the foundation for a psychological contract (Corder \& Ronnie, 2018) between the TMT and employees. In cases of a history of mistrust, keeping the contract is imperative for future management-staff collaboration.

Beyond hospitals, our findings speak to other professional service firms spanning industries such as universities, accounting, law, advertising, banking, IT, and consulting - where achieving change is also particularly challenging because these firms primarily depend on complex technical expertise and the knowledge of its workforce to transform inputs into outputs, which in turn makes these skilled employees, compared with unskilled employees, less likely to engage in change processes (Nordenflycht, 2010).

\section{Managerial Implications}

This paper shows that using the model of cascading change can reconcile topdown and bottom-up approaches to change and result in successful change (in our case, increased productivity and relational coordination (Gittell, 2002) and implementation of solutions). Our model and findings have the following implications for management.

To orchestrate the change process, managers should provide a general direction from project initiation to culmination and define the scope of the project by establishing the boundaries within which solutions from employees must fall. This allows management to simultaneously harness the direction that top-down change management 
provides and the engagement that a bottom-up approach brings. However, the scope should be set sufficiently wide to allow employees ample room to participate in developing solutions they find relevant, care about, and as a result will support implementation.

The model of cascading change, thus, implies that management must delegate problem definition and solution development to employees using means which support collaboration such as workshops. Importantly, this also means that management must accept the proposed solutions if they are within the set scope even if the solutions do not fit managers' personal preferences or situational analysis, for example, due to their area of expertise or responsibility. This managerial acceptance and foundation for reciprocity are central to the psychological contract between management and employees that helps to fuel the model of cascading change. Rejecting employee solutions falling within the scope not only break the psychological contract, but also risk a long-term breach of trust.

To avoid solutions that are out of scope managers must be careful to explain the purpose and theme of the workshops and may provide examples from the data collection that are within the scope of the theme. In this case the notes from work diaries had been sorted into topics and themes which provided ample examples of what was within the scope of each theme.

Managers should note that most if not all employees must participate during the model of cascading change. In orchestrating the process, managers must ensure that employees get involved by providing data (e.g. using work dairies), develop solutions in workshops, and have the opportunity to comment at the culmination workshop before the change solutions get implemented in practice. Involving all employees is costly, resource demanding and requires detailed planning already when orchestrating the process of how to involve and use the information. Despite these costs, we found that they are outweighed 
by the resulting benefits as evident by an increase in relational coordination and ease of implementation.

Transparency is another key element to ensure trust that also has implications for both the change process and managers. Firstly, it means deciding on a suitable format for how to report results from data collection and workshops capable of both communicating transparency and allowing employees to follow the change process. Secondly, transparency also means that managers should refrain from interfering in the agreed change process, edit or make changes to products developed at the employee workshops. A practical solution is to have a project secretary send all project related material to everybody in the department and when doing so note that the material is a product directly from a workshop.

The Lewinian process of unfreeze, move, and refreeze we observed had a long lead time between project initiation and implementation after the culmination workshop thereby potentially going against some managers affinity for executing change fast. One reason for the long lead time is that management and employees go through the processes of unfreeze and move at different speed and points in time, and management will have and experience the longest lead time due to getting involved earlier in the process. However, this is time well spent as getting employees involved in data collection and assigning time for thorough analysis and decision-making result in change solutions that brings employees onboard. Management must therefore be sufficiently patient and allow the cascading change process to unfold and then reap the benefits of easier implementation. 


\section{Conclusion}

Intrigued by the successful outcome of a challenging organizational change project in the cardiology department, our analysis contributes an empirically based 'Model of Cascading Change' that reconcile top-down and bottom-up approaches to change and shed light on how change managers can achieve change successfully. We propose that the model is particularly appropriate in professional service firms where employee autonomy is high and as a means to unlock situations with low employeemanagement trust and poor work environment.

The Model of Cascading Change identifies three enabling change drivers: a cascading change process with structured and transparent handovers between employees tasked with diagnosing, analyzing, and developing solutions; a Lewinian change process occurring at escalating organizational levels that integrate the individual unfreeze, group move, and subsequent organizational refreeze; and an orchestrated change process where management (top-down) provide a general direction for the project and establish the boundaries for employees solutions (bottom-up) which are desired and can be successfully implemented (top-down) by management.

\section{References}

Ackroyd, S., Kirkpatrick, I., \& Walker, R. M. (2007). Public management reform in the $\mathrm{UK}$ and its consequesnces for professional organisation: a comparative analysis. Public Administration, 85(1), 9-26.

Adler, P. S., \& Borys, B. (1996). Two Types of Bureaucracy: Coercive and Enabling. Administrative Science Quarterly, 41(1), 61-89.

Adler, P. S., Heckscher, C., \& Prusak, L. (2011). Building a collaborative enterprise. Harvard Business Review, 89(7), 94-101.

Al-Haddad, S., \& Kotnour, T. (2015). Integrating the organizational change literature: a 
model for successful change. Journal of Organizational Change Management, 28(2), 234-262. https://doi.org/http://dx.doi.org/10.1108/MRR-09-2015-0216

American Hospital Association. (2019). AHA Hospital Statistics.

Ashburner, L., Ferlie, E., \& Fitzgerald, L. (1996). Organizational transformation and top-down change: The case of the NHS. British Journal of Management, 7(1), 116. https://doi.org/10.1111/j.1467-8551.1996.tb00102.x

Bamford, D., \& Forrester, P. L. (2003). A case study into operational team-working within a UK hospital. International Journal of Operations and Production Management, 23(5), 546-564. https://doi.org/10.1108/01443570810856161

Barnett, K., Mercer, S. W., Norbury, M., Watt, G., Wyke, S., \& Guthrie, B. (2012). Epidemiology of multimorbidity and implications for health care, research, and medical education: A cross-sectional study. The Lancet, 380(9836), 37-43. https://doi.org/10.1016/S0140-6736(12)60240-2

Bartunek, J. M., \& Woodman, R. W. (2015). Beyond Lewin: Toward a Temporal Approximation of Organization Development and Change. Annual Review of Organizational Psychology and Organizational Behavior, 2(1), 157-182. https://doi.org/10.1146/annurev-orgpsych-032414-111353

Batalden, P. B. (2019). Every system is perfectly designed to get the results it gets.

Battilana, Julia, \& Casciaro, T. (2013). The network secrets of change agents. Harvard Business Review, 91(7/8), 62-68.

Battilana, Julie, Dimitriadis, S., \& Gargiulo, M. (2012). Change agents, networks, and institutions: A contigency theory of organisational change. Academy of Management Journal, 55(2), 381-398. https://doi.org/10.5465/amj.2009.0891

Beer, M., \& Nohria, N. (2000). Cracking the code of change. Harvard Business Review, 78(3), 133-141. https://doi.org/10.1108/00251740010317423

Brown, J. A., Gianiodis, P. T., Santoro, M. D., \& Brown, J. A. (2015). Following Doctors' Orders: Organizational Change as a Response to Human Capital Bargaining Power. Organization Science, 26(5), 1284-1300.

Buchanan, D., \& Badham, R. (1999). Politics and Organizational Change: The Lived Experience. Human Relations, 52(5), 609-629. https://doi.org/0803973233 
Burnes, B. (2004a). Emergent change and planned change - competitors or allies?: The case of XYZ construction. International Journal of Operations \& Production Management, 24(9), 886-902.

Burnes, B. (2004b). Kurt Lewin and the planned approach to change: A re-appraisal. Journal of Management Studies, 41(6), 977-1002. https://doi.org/10.1111/j.14676486.2004.00463.x

By, R. T. (2005). Organisational change management: A critical review. Journal of Change Management, 5(4), 369-380. https://doi.org/10.1080/14697010500359250

Cameron, K. S., \& Quinn, R. E. (2006). Diagnosing and changing organizational culture: based on the competing values framework. The Jossey-Bass business \& management series. San Francisco, CA: John Wiley \& Sons Inc.

Chatman, J. A., \& Eunyoung Cha, S. (2003). Leading by leveraging culture. California Management Review, 45(4), 20-34. https://doi.org/10.2307/41166186

Cobb, A. T. (1986). Political diagnosis: Applications in organizational development. Academy of Management Review, 11(3), 482-496.

Coch, L., \& French, J. R. P. (1948). OVERCOMING RESISTANCE TO CHANGE. Human Relations, 1, 512-532.

Cocieru, O. C., Lyle, M. C. B., Hindman, L. C., \& McDonald, M. A. (2019). The 'Dark Side' of Psychological Ownership during Times of Change. Journal of Change Management, 7017. https://doi.org/10.1080/14697017.2019.1584121

Coghlan, D. (2011). Organization development and action research. In D. M. Boje, B. Burnes, \& J. Hassard (Eds.), The Routledge Companion to Organizational Change (pp. 46-58). Abingdon: Routledge.

Corder, E., \& Ronnie, L. (2018). The role of the psychological contract in the motivation of nurses. Leadership in Health Services, 31(1), 62-76. https://doi.org/10.1108/LHS-02-2017-0008

Coughlan, P., \& Coghlan, D. (2002). Action research for operations management. International Journal of Operations \& Production Management, 22(2), 220-240. https://doi.org/10.1108/01443570210417515

Coughlan, P., Draaijer, D., Godsell, J., \& Boer, H. (2016). Operations and supply chain 
management: The role of academics and practitioners in the development of research and practice. International Journal of Operations \& Production Management, 36(12), 1673-1695.

Cummings, S., Bridgman, T., \& Brown, K. G. (2016). Unfreezing change as three steps: Rethinking Kurt Lewin's legacy for change management. Human Relations, 69(1), 33-60. https://doi.org/10.1177/0018726715577707

DeLuca, J. R. (1984). Managing the sociopolitical context in planned change efforts. Elements of a framework for practitioners. In A. Kakabadse \& C. Parker (Eds.), Power, Politics, and Organizations: A Behavioural Science View (pp. 127-146). Hoboken, NJ: John Wiley \& Sons.

Dopson, S., Fitzgerald, L., \& Ferlie, E. (2008). Understanding Change and Innovation in Healthcare Settings: Reconceptualizing the Active Role of Context. Journal of Change Management, 8, 213-231. https://doi.org/10.1080/14697010802133577

Dutton, J. E., Ashford, S. J., Neill, R. M. O., \& Lawrence, K. a. (2001). Moves That Matter: Issue Selling and Organizational Change. Academy of Management Journal, 44(4), 716-736.

Eady, S., Drew, V., \& Smith, A. (2015). Doing action research in organizations: Using communicative spaces to facilitate (transformative) professional learning. Action Research, 13(2), 105-122.

Edmondson, A. (1999). Psychological Safety and Learning Behavior in Work Teams. Administrative Science Quarterly, 44(2), 350-383. https://doi.org/10.2307/2666999

Edwards, K., \& Winkel, J. (2018). A method for effect modifier assessment (EMA) in ergonomic intervention research. Applied Ergonomics, 72. https://doi.org/10.1016/j.apergo.2018.05.007

Edwards, Kasper, \& Winkel, J. (2018). A method for effect modifier assessment (EMA) in ergonomic intervention research. Applied Ergonomics, (In press).

Ford, J. D., \& Ford, L. W. (1995). The Role of Conversations in Producing Intentional Change in Organizations. Academy of Management Review, 20(3), 541-570.

Ford, J. D., \& Ford, L. W. (2009). Resistance to change: A reexamination and extension. Research in Organizational Change and Development, 17, 211-239. 
https://doi.org/10.1108/S0897-3016(2011)0000019004

Ford, J. D., Ford, L. W., \& D’Amelio, A. (2008). Resistance to Change: The Rest of the Story. Academy of Management Review, 33(2), 362-377.

Fuchs, S., \& Prouska, R. (2014). Creating Positive Employee Change Evaluation: The Role of Different Levels of Organizational Support and Change Participation. Journal of Change Management, 14(3), 361-383.

Garman, A. N., Leach, D. C., \& Spector, N. (2006). Worldviews in collision : Conflict and collaboration across professional lines. Journal of Organizational Behavior, 27, 829-849.

Gittell, J. H. (2002). Coordinating Mechanisms in Care Provider Groups: Relational Coordination as a Mediator and Input Uncertainty as a Moderator of Performance Effects. Management Science, 48(11), 1408-1426.

Grant, A. M., \& Wall, T. D. (2009). The neglected science and art of quasiexperimentation: Why-to, when-to, and how-to advice for organizational researchers. Organizational Research Methods (Vol. 12). https://doi.org/10.1177/1094428108320737

Heldal, F. (2015). Managerial Control versus Professional Autonomy in Organizational Change: Tearing Down the Walls and Fighting Fire with Fire. Journal of Change Management, 15(3), 188-209. https://doi.org/10.1080/14697017.2015.1028573

Heracleous, L., \& Barrett, M. (2001). Organizational Change as Discourse: Communicative Actions and Deep Structures in the Context of Information Technology Implementation. Academy of Management Journal, 44(4), 755-778.

Hermann Global. (2019). Whole Brain ${ }^{\circledR}$ Thinking: How it works. Retrieved from https://www.thinkherrmann.com/how-it-works

Heyden, M. L. M., Fourné, S. P. L., Koene, B. A. S., Werkman, R., \& Ansari, S. (Shaz). (2016). Rethinking 'Top-Down' and 'Bottom-Up' Roles of Top and Middle Managers in Organizational Change: Implications for Employee Support. Journal of Management Studies, (Online ahead of print), 1-45. https://doi.org/10.1111/joms.

Hughes, M. (2011). Do 70 Per Cent of All Organizational Change Initiatives Really Fail? Journal of Change Management, 11(4), 451-464. 
https://doi.org/10.1080/14697017.2011.630506

Huy, Q. N. (2001). Time, Temporal Capability, and Planned Change. Academy of Management Journal, 26(4), 601-623.

Huy, Q. N., \& Mintzberg, H. (2003). The rhythm of change. MIT Sloan Management Review, 44(4), 79-84.

Institute of Medicine. (2013). Best Care at Lower Cost: The Path to Continuously Learning Health Care in America. (M. Smith, R. Saunders, L. Stuckhardt, \& J. M. McGinnis, Eds.). Washington, DC: The National Academies Press.

Isabella, L. A. (1990). Evolving interpretations as a change unfolds : How managers construe key organizational events. Academy of Management Journal, 33(1), 7-41. https://doi.org/10.2307/256350

Jimmerson, C. L. (2007). A3 problem solving for healthcare: a practical method for eliminating waste. Boca Raton, FL: CRC Press.

Kanter, R. M., Stein, B. A., \& Jick, T. D. (1992). The Challenge of Organizational Change. New York: The Free Press.

Kim, W. C., \& Mauborgne, R. (1998). Procedural justice, strategic decision making, and the knowledge economy. Strategic Management Journal, 19(4), 323-338.

Kotter, J. P. (1995). Leading change: Why transformation efforts fail. Harvard Business Review, 73(2), 59-67.

Kotter, J. P., \& Schlesinger, L. A. (2008). Choosing strategies for change. Harvard Business Review, 86(7/8), 130-139.

Laine, P., \& Kuoppakangas, P. (2015). A Reconceptualization of Change Strategy One Application of Dilemma Theory. Journal of Change Management, 15(4), 332-352. https://doi.org/10.1080/14697017.2015.1058845

Langley, A. (1999). Strategies for theorizing from process data. Academy of Management Review, 24(4), 691-710. https://doi.org/10.5465/AMR.1999.2553248

Lapointe, L., \& Rivard, S. (2005). A Multilevel Model of Resistance to Information Technology Implementation. MIS Quarterly, 29(3), 461-491.

Lewin, K. (1947). Frontiers in Group Dynamics: Concept, Method and Reality in Social Science; Social Equilibria and Social Change. Human Relations, 1(1), 5-41. 
https://doi.org/10.1177/001872674700100103

Lines, R. (2004). Influence of participation in strategic change: resistance, organizational commitment and change goal achievement. Journal of Change Management, 4(3), 193-215.

Lines, R. (2005). The Structure and Function of Attitudes Toward Organizational Change. Human Resource Development Review, 4(1), 8-32.

Lines, R., Selart, M., Espedal, B., \& Johansen, S. T. (2005). The production of trust during organizational change. Journal of Change Management, 5(2), 221-245.

Maitlis, S., \& Sonenshein, S. (2010). Sensemaking in crisis and change: Inspiration and insights from Weick (1988). Journal of Management Studies, 47(3), 551-580.

Marti, J. (2016). Measuring in action research: Four ways of integrating quantitative methods in participatory dynamics. Action Research, 14(2), 168-183.

McDermott, A. M., Fitzgerald, L., \& Buchanan, D. A. (2013). Beyond Acceptance and Resistance: Entrepreneurial Change Agency Responses in Policy Implementation. British Journal of Management, 24, S93-S115. https://doi.org/10.1111/14678551.12012

McNulty, T., \& Ferlie, E. (2004). Process Transformation: Limitations to Radical Organizational Change within Public Service Organizations. Organization Studies, 25(8), 1389-1412. https://doi.org/10.1177/0170840604046349

Meyer, A. D., Goes, J. B., \& Brooks, G. R. (1993). Organizations reacting to hyperturbulence. In G. P. Huber \& W. H. Glick (Eds.), Organizational change and redesign (pp. 66-111). New York, NY: Oxford University Press.

Meyer, C. B., \& Stensaker, I. G. (2006). Developing capacity for change. Journal of Change Management, 6(2), 217-231. https://doi.org/10.1080/14697010600693731

Mintzberg, H., \& Glouberman, S. (2001). Managing the care of health and the cure of disease-Part I: Differentiation. Health Care Management Review, 26(1), 56-69.

Nielsen, J. F., \& Riiskjær, E. (2013). From Patient Surveys to Organizational Change: Rational Change Processes and Institutional Forces. Journal of Change Management, 13(2), 179-205. https://doi.org/10.1080/14697017.2012.745584

Nielsen, K. (2013). Review Article: How can we make organizational interventions 
work? Employees and line managers as actively crafting interventions. Human Relations, 66(8), 1029-1050.

Nordenflycht, A. von. (2010). What is a Professional Service Firm? Towards a Theory and Taxonomy of Knowledge Intensive Firms. Academy of Management Review, 35(1), 155-174.

Orlikowski, W. J. (1996). Improvising organisational transformation overtime: a situated change perspective. Information Systems Research, 7(1), 63-92.

Palmer, I., Akin, G., \& Dunford, R. (2009). Managing Organizational Change: A Multiple Perspectives Approach. New York, NY: McGraw-Hill Higher Education.

Piderit, S. K. (2000). Rethinking Resistance and Recognizing Ambivalence: A Multidimensional View of Attitudes toward an Organizational Change. Academy of Management Review, 25(4), 783-794.

Powell, A., \& Davies, H. (2012). The struggle to improve patient care in the face of professional boundaries. Social Science \& Medicine, 75(5), 807-814.

Preget, L. (2013). Understanding Organizational Change as an Interactional Accomplishment: A Conversation Analytic Approach. Journal of Change Management, 13(3), 338-361. https://doi.org/10.1080/14697017.2013.822675

Rafferty, A. E., Jimmieson, N. L., \& Armenakis, A. (2013). Change Readiness: A Multilevel Review. Journal of Management, 39(1), 110-135.

Ramanujam, R., \& Rousseau, D. M. (2006). The challenges are organizational not just clinical. Journal of Organizational Behavior, 27(7), 811-827.

Rousseau, D. M. (1989). Psychological and implied contracts in organizations.

Employee Responsibilities and Rights Journal, 2(2), 121-139.

https://doi.org/10.1007/BF01384942

Schein, E. H. (2004). Organizational culture and leadership. The Jossey-Bass business \& management series (Vol. 3.). San Francisco, CA: Jossey-Bass.

Scott, W. R., Ruef, M., Caronna, C. A., \& Mendel, P. J. (2000). book review:

Institutional Change and Healthcare Organizations: From Professional Dominance to Managed Care. Chicago: University of Chicago Press. International Journal of Integrated Care, 2(March), 194-196. Retrieved from 
http://www.press.uchicago.edu/ucp/books/book/chicago/I/bo3631315.html

Shani, A. B. (Rami), Mohrman, S. A., Pasmore, W. A., Stymne, B., \& Adler, N. (Eds.). (2007). Handbook of Collaborative Management Research. Los Angeles, CA: SAGE Publications.

Shaw, P. (1997). Intervening in the shadow systems of organizations: Consulting from a complexity perspective. Journal of Organizational Change Management, 10(3), $235-250$.

Sirkin, H. L., Keenan, P., \& Jackson, A. (2005). The hard side of change management. Harvard Business Review, 83(10), 108-118.

Sonenshein, S., \& Sonenshein, S. (2016). We're Changing - or are we? Untangling the Role of Progressive, Regressive, and Stability Narratives During Strategic Change Implementation. Academy of Management Journal, 53(3), 477-512. https://doi.org/10.1016/j.indcrop.2007.07.013

Strauss, A. L., Fagerhaugh, S., Suczek, B., \& Wiener, C. (1997). Social organization of medical work. New Brunswick: Transaction.

Tushman, M. L., \& Romanelli, E. (1985). Organizational evolution: A metamorphosis model of convergence and reorientation. Research in Organizational Behavior, 7, $171-222$.

Van De Ven, A. H., Poole, S., \& Poole, M. S. (1995). Explaining Development and Change in Organizations. Academy of Management Review, 20(3), 510-540. https://doi.org/10.2307/258786

Van Elst, D., \& Meurs, D. (2016). Positive Management: the Relationship Between the Psychological Contract, Employee Engagement and Organisational Commitment. Journal of Positive Management, 6(4), 39. https://doi.org/10.12775/jpm.2015.021

Walton, R. E. (1985). FROM CONTROL TO COMMITMENT IN THE WORKPLACE. Harvard Business Review, 63(2), 776-784.

Weick, K. E., \& Quinn, R. E. (1999). Organizational Change and Development. Annual Review of Psychology, 50, 361-386.

Yin, R. K. (2009). Case study research : design and methods. Sage. Retrieved from https://findit.dtu.dk/en/catalog?q=robert $+\mathrm{k}+$ yin+2009\&type=book_printed\&utf8= 
